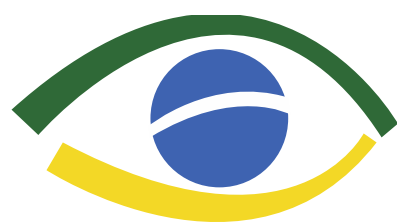

Observatório da Jurisoliçãc

Constitucional
Observatório da Jurisdição Constitucional. Ano 7, no. 1, jan./jun. 2014. ISSN 1982-4564.

\title{
O ativismo judicial do Supremo Tribunal Federal no julgamento da Lei da Ficha Limpa
}

Raquel Botelho Santoro

Resumo: O presente artigo analisa, inicialmente, um conceito de ativismo judicial e seus pressupostos, para posteriormente demonstrar como o Supremo Tribunal Federal adotou uma postura ativista no julgamento da constitucionalidade da chamada Lei da Ficha Limpa.

Palavras-chave: Lei da Ficha Limpa; ativismo judicial; presunção de inocência; atividade jurisdicional.
Abstract: this work analyzes, initially, one concept of judicial activism and its characteristics, in order to demonstrate how the Brazilian Supreme Court adopted an activist posture when analyzing the constitutionality of the "Ficha Limpa" Bill.

Keywords: Ficha Limpa Bill, judicial activism, innocence presumption, judicial activity

\footnotetext{
* Mestre e Doutoranda em Direito Constitucional pela Faculdade de Direito da Universidade de São Paulo. Graduada em Direito pela Universidade de Brasília. Advogada.
} 


\section{1. $O$ conceito de ativismo judicial que adotaremos nesse trabalho}

O presente artigo busca analisar, em breves considerações, a posição do Supremo Tribunal Federal no julgamento da constitucionalidade da chamada Lei da Ficha Limpa, fazendo para tanto um exame do conceito de ativismo judicial e a sua aplicabilidade concreta na jurisdição constitucional brasileira.

Para isso, vamos focar a nossa análise em um caso concreto cujo desfecho agradou a grande parte da população brasileira, mas que, a nosso ver, representou exemplo de ativismo judicial reprovável, com contornos sociais que deveriam ser evitados pela jurisdição constitucional.

Antes de tudo, porém, é imprescindível definir o conceito de ativismo judicial que presidirá nossas análises ${ }^{1}$. Para tanto, adotaremos a posição do Professor Elival da Silva Ramos, que define o ativismo judicial como "o exercício da função jurisdicional para além dos limites impostos pelo próprio ordenamento que incumbe, institucionalmente, ao Poder Judiciário fazer atuar, resolvendo litígios de feições subjetivas (conflitos de interesse) e controvérsias jurídicas de natureza objetiva (conflitos normativos) ${ }^{, 2}$.

O ativismo, assim, pressupõe que haja liberdade de interpretação dos juízes na aplicação das regras, dos princípios e, principalmente, onde ele é mais observado, na concretização das normas constitucionais. Isso porque, sendo mais fluidas, programáticas e, na maioria das vezes, de eficácia limitada, as normas constitucionais são aquelas que dão

\footnotetext{
${ }^{1}$ É importante adotar já desde o início um conceito de ativismo judicial com o qual trabalharemos, porque o ativismo, por vezes, é também considerado apenas uma forma mais assertiva ou contundente de atuação judicial, como para Frederick P. Lewis, para quem "the activism will be used in this book simply to characterize a Court willing to use its authority to engage in judicial review in an assertive manner. Such assertiveness will also imply here a considerable degree of doctrinal pronouncement that is innovative, at least in the sense that it has not been explicitly pronounced before. The term activist will be employed in opposition to describing a Court as 'restrained' in the use of its authority and in the development of doctrine." LEWIS, Frederick P. The Context of Judicial Activism - the endurance of the Warren Court legacy in a Conservative Age. Lanham: Rowman \& Littlefield Publisher Inc., 1999. p. 7.

${ }^{2}$ RAMOS, Elival da Silva. Ativismo Judicial. Parâmetros Dogmáticos. São Paulo: Saraiva, 2010. pp. 129 e 308. No mesmo sentido é o conceito de Kermit Roosevelt III: "The basic question this book sets out to answer is how we can decide whether a particular judicial decision is legitimate. The distinction between legitimate and illegitimate decisions is meant to do what the concept of activism claims to do, but fails: to distinguish between decisions that should be accepted and those that should be condemned or opposed. What I meant by a legitimate decision is essentially an appropriate exercise of judicial authority. Citizens or government officials may disagree with a legitimate decision, but it provides no basis for charging that the judges have exceeded theirs proper role." ROOSEVELT III, Kermit. The Myth of Judicial Activism - making sense of Supreme Court Decisions. New Haven: Yale University Press, 2006 (versão para kindle), p. 37.
} 
maior espaço de interpretação aos juízes, os quais, na sua aplicação, estão mais sujeitos a incorrer no ativismo.

Conforme se verifica na prática atual da jurisdição constitucional, importante papel no contexto do denominado ativismo judicial possuem a técnica da ponderação ${ }^{3}$ e a teoria dos direitos fundamentais como princípios, tendo em vista a abertura ao subjetivismo do intérprete, reconhecida pelos próprios aplicadores e filósofos dessa teoria ${ }^{4}$, não obstante tenham eles desenvolvido técnicas diversas para assegurar a racionalidade dos procedimentos.

É relevante ainda considerar que, para fins do presente trabalho, entenderemos o ativismo judicial invariavelmente como um fenômeno negativo, na esteira do que adverte Elival da Silva Ramos quando diferencia a caracterização do fenômeno nos países de common law e naqueles de civil law ${ }^{5}$. E o caráter negativo do fenômeno será consequência direta do conceito por nós adotado e que pressupõe a "exacerbação no exercício da função judicante"

Tendo em vista que o ponto central para a definição do ativismo judicial reside na constatação da atuação judicial em parâmetros que extrapolem os limites da atividade jurisdicional, resta-nos imprescindível tentar definir esses limites para que possamos mediante a análise do caso concreto que nos propusemos a examinar - perceber ou não a configuração do fenômeno na atuação do Supremo Tribunal Federal.

\footnotetext{
${ }^{3}$ Alexy define da seguinte forma a lei da ponderação: "Cuanto mayor sea el grado de la no satisfacción o de afectación de uno de los principios, tanto mayor debe ser la importancia de la satisfacción del otro.” ALEXY, Robert. Teoría de los Derechos Fundamentales. Madrid: Centro de Estudios Políticos y Constitucionales, 2007, p. 529. E, ainda, "[o] juízo de ponderação, como entendido hoje, vincula-se à ideia de que as normas podem assumir a forma de princípios, comportando, por isso, mitigação na intensidade de sua incidência sobre casos concretos quando em conflito com outras normas, mantendo, contudo, sua validez jurídica." BRANCO, Paulo Gustavo Gonet. Juízo de Ponderação na Jurisdição Constitucional. São Paulo: Saraiva, 2009, p. 146. Ana Paula de Barcellos, por sua vez, define a ponderação de forma geral e não apenas aplicada aos conflitos entre direitos fundamentais, vejamos: "De forma muito geral, a ponderação pode ser descrita como uma técnica de decisão própria para casos difíceis (do inglês 'hard cases'), em relação aos quais o raciocínio tradicional da subsunção não é adequado." BARCELLOS, Ana Paula de. Alguns Parâmetros Normativos para a Ponderação Constitucional. in: BARROSO, Luís Roberto (org.) A Nova Interpretação Constitucional - Ponderação, Direitos Fundamentais e Relações Privadas. Rio de Janeiro: Renovar, 2006. p. 55. Ainda sobre a ponderação e sobre uma interessante técnica de aplicação que tenta conciliá-la com juízos de subsunção, vide MORESO, José Juan. Conflictos entre Principios Constitucionales. in: CARBONELL, Miguel (org.) Neoconstitucionalismo(s). Madrid: Editorial Trotta, 2009.

${ }^{4}$ ALEXY, Robert. Teoría de los Derechos... Op. cit., p. 130 e seguintes.

5 'Não há, pois, necessariamente, um sentido negativo na expressão 'ativismo', com alusão a uma certa prática de jurisdição. Ao contrário, invariavelmente o ativismo é elogiado por proporcionar a adaptação do direito diante de novas exigências sociais e de novas pautas axiológicas, em contraposição ao 'passivismo', que, guiado pelo propósito de respeitar as opções do legislador ou dos precedentes passados, conduziria a estratificação dos padrões de conduta normativamente consagrados." RAMOS, Elival da Silva. Op. cit. p. 110.

${ }^{6}$ RAMOS, Elival da Silva. Op. cit. p. 129.
} 


\subsection{A tentativa de definição dos limites da função jurisdicional}

Colocadas essas premissas introdutórias, passemos, então, à análise específica do ativismo judicial no contexto do ordenamento brasileiro.

Pelo exposto, para que se caracterize o ativismo é necessário que o Poder Judiciário exacerbe a atividade jurisdicional, invadindo a esfera de funções de outros poderes, notadamente do Legislativo, ou simplesmente utilizando por base de seu posicionamento fundamentos inexistentes no ordenamento legal e constitucional.

O primeiro obstáculo na aplicação do conceito acima se encontra na necessidade de se definir o que seria a função jurisdicional, para que então se pudesse constatar quando ela fosse exacerbada. É o que tentaremos fazer em seguida.

Comecemos por observar que a Constituição brasileira, em seu artigo 102, atribuiu ao Supremo Tribunal Federal, precipuamente, a guarda da Constituição Federal ${ }^{7}$.

Essa função de guardar a Constituição também é atribuída aos entes políticos da União, dos Estados, do Distrito Federal e dos Municípios, no artigo 23 do diploma constitucional $^{8}$.

Dessa atribuição decorre, por exemplo, o poder do Supremo Tribunal Federal de declarar inconstitucional uma lei aprovada pelo Congresso Nacional, em ato que poderia ser considerado como uma invasão à autonomia do Poder Legislativo, mas que é justificado sob o argumento de salvaguarda e supremacia da Carta Magna.

Daí temos que a função jurisdicional, além da tradicional atribuição de resolver os conflitos que a ela são propostos, também possui, hoje, a atribuição de definir, em abstrato, a conformidade de um ato normativo com a Constituição, podendo revogá-lo em caso de inconstitucionalidade.

Ocorre que a função de guarda da Constituição não se restringe à prerrogativa de exercer o controle de constitucionalidade. Por guarda da Constituição devemos entender também o exercício de funções que visem à preservação de seus valores, o que pode ser feito tanto mediante a determinação de observância de seus termos pelos cidadãos e pelo Poder Público, quanto mediante a rejeição dos atos - comissivos ou omissos, dos cidadãos ou do Poder Público - que estejam em desacordo com os seus termos.

\footnotetext{
${ }^{7}$ Art. 102. Compete ao Supremo Tribunal Federal, precipuamente, a guarda da Constituição, cabendo-lhe: (...).

${ }^{8}$ Art. 23. É competência comum da União, dos Estados, do Distrito Federal e dos Municípios:

I - zelar pela guarda da Constituição, das leis e das instituições democráticas e conservar o patrimônio público;
} 
Essa perspectiva, inclusive, é consequência direta da compreensão dos direitos fundamentais como conformadores de uma ordem objetiva de valores a traduzirem duas funções essenciais desses direitos: os deveres de proteção do Estado - aos quais correspondem direitos subjetivos dos cidadãos a verem protegidos e realizados esses direitos - e sua eficácia irradiante.

A atividade jurisdicional, portanto, é mais do que a mera observância dos parâmetros legais previamente estabelecidos pelo legislador. Ela implica, também, a função de guarda da Constituição; ou seja, a responsabilidade não só de cumprir os valores constitucionais e fazer cumpri-los, mas também de rechaçar o seu descumprimento, tanto mediante a anulação de atos positivos de violação, quanto mediante a reforma dos atos omissivos que também impliquem transgressão.

Nesse sentido, é também importante observar que, especificamente em relação aos direitos fundamentais, a própria Constituição Federal ${ }^{9}$ é clara ao dispor que eles deverão ter aplicação imediata - ou seja, independente de qualquer regulamentação -, a qual deveria ser necessariamente assegurada pelos intérpretes e guardiões da Constituição.

A análise acima deve ser ainda complementada por considerações acerca da nova hermenêutica constitucional que privilegia a força normativa dos princípios e a sua concretização.

Esse novo paradigma de interpretação prega, como diretriz, a conferência de especial relevância aos princípios constitucionais, como fundadores de uma ordem objetiva de valores, sob o argumento de preservação da própria força normativa da Constituição ${ }^{10}$.

Ao contrário do que os críticos dessas balizas de interpretação constitucional muitas vezes deixam transparecer ${ }^{11}$, essa nova visão dos princípios constitucionais não é um

\footnotetext{
${ }^{9}$ Art. $5^{\text {o }}$ Todos são iguais perante a lei, sem distinção de qualquer natureza, garantindo-se aos brasileiros e aos estrangeiros residentes no País a inviolabilidade do direito à vida, à liberdade, à igualdade, à segurança e à propriedade, nos termos seguintes: (...)

$\S 1^{\circ}$ - As normas definidoras dos direitos e garantias fundamentais têm aplicação imediata.

${ }^{10}$ A esse respeito, Alexy cita o seguinte posicionamento do Tribunal Alemão: "De acuerdo con la jurisprudencia permanente del Tribunal Constitucional Federal, las normas de derecho fundamental contienen no sólo derechos subjetivos de defensa del individuo frente al Estado, sino que representan, al mismo tempo, un orden de valorativo objetivo que, en tanto decisión básica de derecho constitucional, es válida para todos los ámbitos del derecho y proporciona directrices e impulsos para la legislación, la administración y la jurisdicción (BVerfGE 39, 1 (41)" ALEXY, Robert. Teoría de los Derechos, Op. cit., p. 465. Ingo Wolfgang Sarlet, citando Alexy, comenta que a expressão "ordem objetiva de valores" pode ser entendida como um sinônimo de dimensão objetiva dos direitos fundamentais, assim como outras expressões como "sistema de valores, decisões constitucionais fundamentais, direitos fundamentais como normas objetivas, diretrizes e impulsos, etc." SARLET, Ingo Wolfgang. A Eficácia dos Direitos Fundamentais. Porto Alegre: Livraria do Advogado, 2007, p. 167.
} 
movimento exclusivamente ideológico e tem bases sólidas na própria conformação da Constituição brasileira.

Isso porque a Constituição Federal de 1988 não só optou pela regulação excessiva das matérias políticas, como também previu, por meio de seus próprios dispositivos, instrumentos aptos a conferir ao Judiciário esse poder de interpretação alargada. Desse modo, o estabelecimento de diversos princípios e de dispositivo constitucional que impõe deva a sua aplicação ser feita de forma imediata $\left(\mathrm{CF} \text {, artigo } 5^{\circ}, \S 1^{\circ}\right)^{12}$ estimulam essa nova hermenêutica e dão margem a um papel cada vez mais expansivo do Poder Judiciário, remodelando as balizas da atividade jurisdicional, como acima demonstrado.

Ainda na esteira dessas disposições constitucionais que conferem maiores poderes ao Judiciário, a Emenda Constitucional n 45/04 atribuiu ao Supremo Tribunal Federal o poder de editar súmulas vinculantes, que deveriam ser enunciados decorrentes de reiteradas decisões da Suprema Corte, utilizados para nortear a atuação não só dos demais órgãos do Poder Judiciário, mas também dos órgãos administrativos. Referido instrumento atribuiu ao Supremo Tribunal Federal poder normativo explícito, alargando ainda mais os limites da atividade jurisdicional.

Contudo, essas novas balizas e parâmetros de atuação do Judiciário - em especial no âmbito da jurisdição constitucional, no que diz respeito ao objeto do nosso trabalho - são alvo de preocupações diversas, como aquelas apresentadas tanto por Elival da Silva Ramos quanto por Humberto Ávila, esse último com foco na aplicação acrítica do neoconstitucionalismo ${ }^{13}$.

Ambos apresentam como justificativa dessa preocupação, dentre outras, a necessidade de se observarem os postulados do Estado de Direito que, segundo eles, estariam ameaçados por essa postura denominada de ativista.

Humberto Ávila dá continuidade a sua crítica com ênfase nos aspectos conformadores do neoconstitucionalismo, o qual considera como causa e consequência do ativismo judicial.

\footnotetext{
11 ÁVILA, Humberto. Neoconstitucionalismo: entre a "ciência do direito" e o "direito da ciência". in: Vinte anos da Constituição Federal de 1988. Rio de Janeiro: Lumen Juris, 2009. p. 187 a 202.

${ }^{12}$ Exatamente nesse sentido é a análise de Manoel Gonçalves Ferreira Filho. O Papel Político do Judiciário e suas Implicações. in: Systemas, Revista de Ciências Jurídicas e Econômicas. Ano 1, n. 2. Disponível em: http://www.revistasystemas.com.br/index.php/systemas/article/view/21/16. Acesso em 24.03.2014.

13 “Conviene tener presente, con todo, que cuando se habla de neoconstitucionalismo, ya sea en singular o en plural, se está haciendo referencia a dos cuestiones que deben estudiarse por separado. Por una parte, como ya se ha mencionado, a una serie de fenómenos evolutivos que han tenido evidentes impactos en lo que se ha llamado el paradigma del Estado constitucional. Por otro lado, con el término 'neoconstitucionalismo' se hace referencia también a una determinada teoría del Derecho que ha propugnado en el pasado reciente por esos cambios y/o que da cuenta de ellos, normalmente en términos bastante positivos o incluso elogioso." CARBONELL, Miguel. Prólogo: nuevos Tiempos Para El Constitucionalismo. in: CARBONELL, Miguel (org.) Op. cit., pp. 9-10.
} 
Nas suas palavras, esse neoconstitucionalismo configurar-se-ia em quatro diversos aspectos: (i) normativo, segundo o qual a Constituição veicula mais princípios do que regras ${ }^{14}$; (ii) metodológico, segundo o qual o eixo de aplicação passa do método de subsunção para o de ponderação; (iii) axiológico, segundo o qual há uma inversão na aplicação da justiça, que passa a ser individual, em substituição à justiça geral ${ }^{15}$; e (iv) organizacional, quando se verificaria, em decorrência dos três aspectos anteriores, a prevalência do Poder Judiciário sobre o Legislativo.

Nesse sentido, Humberto Ávila faz as seguintes considerações:

(...) o Poder Judiciário não deve assumir, em qualquer matéria e em qualquer intensidade, a prevalência na determinação da solução entre conflitos morais porque, num Estado de Direito, vigente numa sociedade complexa e plural, deve haver regras gerais destinadas a estabilizar conflitos morais e reduzir a incerteza e a arbitrariedade decorrente da sua inexistência ou desconsideração, cabendo a sua edição ao Poder Legislativo e a sua aplicação, ao Judiciário. ${ }^{16}$

Elival da Silva Ramos, por sua vez, pontua que é

(...) indispensável, à luz do ideário democrático, trabalhar a teoria constitucional sob as premissas de um positivismo renovado pelas conquistas da moderna Hermenêutica, situando a discricionariedade envolvida na tarefa de atuação da Constituição no plano estritamente dogmático e submetendo tanto o legislador, ao concretizar na lei comandos constitucionais, quanto o juiz, ao escolher entre diferentes possibilidades exegéticas, às exigências do Estado de Direito. ${ }^{17}$

\footnotetext{
14 Alguns críticos chegam até mesmo a dizer que os juízes ativistas modificam o significado dos termos constantes da Constituição, como é a posição de Sutherland a respeito da interpretação dada pela Suprema Corte dos EUA à Primeira Emenda. Segundo ele, referido dispositivo não pode ser interpretado como a separação entre Estado e religião, como pretendem fazer crer juízes e advogados diversos, em interpretação distorcida e, na visão dele, inaceitável. "Judges are applying similar principles to laws established by the Constitution. And wellmeaning people, even Christians, have the false assumption that what a judge says is law. This defies our very system of government. Our system of government gave the power of lawmaking to Congress, not the judges. And when a judge changes the definition of words within a law, he is making a new law, and that is illegal, not to mention unconstitutional." SUTHERLAND, Mark I. Redefining the Rules. In: SUTHERLAND, Mark I. (org.) Judicial Tyranny - the new kings of america? Saint louis: Amerisearch, 2007 (versão para kindle). Posição 902 de 3119.

15 Nesse mesmo sentido é o alerta feito por CARRESE, Paul O. The Cloaking of Power - Montesquieu, Blackstone and the Rise of Judicial Activism. Chicago: The University of Chicago Press, 2003 (versão para kindle). pp. 258-259.

${ }^{16}$ ÁVILA, Humberto. Op. cit. pp. 26/27.

${ }^{17}$ RAMOS, Elival da Silva. Op. cit., p. 307.
} 
Ocorre que o Estado de Direito, por sua vez, pode ser caracterizado pela observância e respeito aos seguintes princípios: republicano, democrático, da dignidade da pessoa humana, da separação dos Poderes, do pluralismo político, da isonomia e da legalidade.

Tais críticas, contudo, parecem reduzir o primado do Estado de Direito apenas ao princípio da legalidade, conferindo a ele primazia sobre todos os demais postulados que conformam o conceito. Portanto, parecem ser extremamente frágeis diante de suas próprias premissas, mesmo porque a postura ativa do Judiciário confere primazia aos demais princípios que compõem o Estado de Direito, sem ferir o princípio da legalidade que tanto inquieta esses dois críticos.

A preocupação de ambos os autores com a preservação do princípio da separação dos poderes também se mostra nítida. Elival da Siva Ramos cita, como exemplo de intervenção indevida nesse postulado, o exercício de atividade normativa por parte do Poder Judiciário como aquela decorrente da edição de súmulas vinculantes.

Humberto Ávila, por sua vez, nem chega a mencionar o exercício do poder legiferante pelo Judiciário, restringindo-se a considerar que a possibilidade de aplicação dos princípios, por meio da ponderação, em sobreposição às regras legais aparentemente válidas, já implicaria intervenção suficientemente indevida de um poder no outro ${ }^{18}$.

Contudo, sabe-se que o princípio da separação dos poderes não significa a divisão estanque de tarefas e muito menos a impossibilidade de que um Poder exerça, ainda que de forma moderada e circunstancial, atividades de competência originária de outro Poder.

A doutrina da separação dos poderes já sofreu diversas mitigações com o desenvolvimento político das nações ${ }^{19}$ e, apesar de ser um corolário intrínseco à caracterização de um Estado de Direito, permite hoje diversas ponderações de sentido e valor

\footnotetext{
${ }^{18}$ Sobre contestação às críticas de Humberto Ávila, vide SILVA, Virgílio Afonso da. Direitos Fundamentais conteúdo essencial, restrições e eficácia. São Paulo: Malheiros, 2009, pp. 56-64.

${ }^{19}$ Víctor Ferreres Comella aponta, inclusive, que o desenvolvimento da teoria da separação dos poderes se deu de formas diversas na Europa e nos Estados Unidos. Isso porque, enquanto na Europa a desconfiança se observava principalmente em relação ao Judiciário, nos Estados Unidos essa desconfiança era voltada ao Parlamento. Portanto, na Europa se conferiu desde logo menos possibilidades de atuação ao Judiciário, ao passo que nos EUA essa possibilidade de atuação já era aceita, ainda que não houvesse consenso sobre a sua extensão. COMELLA, Víctor Ferreres. Constitutional Courts \& Democratic Values - a european perspective. New Haven: Yale University Press, 2009. pp. 10-15. Ver também REHNQUIST, William H. The Supreme Court. New York: Vintage Books, sem indicação de ano (versão para Kindle). Posição 4557 de 4920. No mesmo sentido são os apontamentos de Stephen Powers e Stanley Rothman a respeito da desconfiança dos norte-americanos em relação aos burocratas e funcionários públicos, o que, para eles, foi um dos fatores que desencadeou o desenvolvimento de um Judiciário cada vez mais ativo naquele país. POWERS, Stephen P. E ROTHMAN, Stanley. The Least Dangerous Branch? Consequences of Judicial Activism. Westport: Praeger, 2002 (versão para kindle), posição 2920 de 3392.
} 
as quais, de certa forma, justificam algumas intromissões de uns poderes em funções tradicionalmente atribuídas aos outros ${ }^{20}$.

$\mathrm{Na}$ esteira dessa necessidade de adaptar a concepção tradicional de separação de poderes, Karl Loewenstein propõe um novo modelo tripartite, sobre o qual se manifesta da seguinte maneira:

Es difícil desalojar un esquema mental que está profundamente enraizado, y el dogma de la separación de poderes es el más sagrado de la teoría y práctica constitucional. El iconoclasta no puede sentirse satisfecho con sólo remover de su pedestal al ídolo de la triple separación del orden del dominio en los 'poderes' legislativo, ejecutivo y judicial; en su lugar estará obligado a colocar otro análisis de la dinámica del poder más de acuerdo con la sociedad pluralista de masas de nuestro siglo. A continuación se expone una nueva división tripartita: la decisión política conformadora o fundamental (policy determination); la ejecución de la decisión (policy execution) y el controle político (policy control). ${ }^{21}$

Na prática, essa nova conformação da teoria da separação dos poderes também é claramente perceptível. No Brasil, por exemplo, são facilmente identificados exemplos de atuação dos Poderes em funções tradicionalmente atribuídas a outros, como na edição de medidas provisórias pelo Poder Executivo, ou no caso aqui já mencionado da edição de súmulas vinculantes pelo Poder Judiciário.

Todavia, tanto nessas como em outras atividades, um Poder não fica imune à fiscalização dos demais, sempre atentando-se para a aplicação da teoria dos freios e contrapesos, de modo que se permita a interpenetração de referidos poderes e a interfiscalização de todas as atividades realizadas; portanto, se afigura a improcedência da crítica também no que tange a esse aspecto da realidade.

Outra crítica muito frequente atribuída ao ativismo judicial é a de que ele reduziria o espaço de atuação política da sociedade, que passaria a recorrer ao Judiciário para fazer valer

\footnotetext{
${ }^{20}$ É interessante a ponderação feita pelos Professores norte-americanos Nowak e Rotunda sobre a nova conformação da separação dos poderes: "While people sometimes refer to the three branches of the federal government as a three-layer cake, it is more accurate to think of it as a marble cake. For example, Congress enacts legislation, but the President can veto it, and Congress can override the veto. The judiciary is independent, but the President appoints the judges, who must be confirmed by the Senate". Em tradução livre: "Enquanto as pessoas muitas vezes se referem aos três ramos do governo federal como um bolo de três camadas, é mais preciso pensar a respeito como um bolo marmorizado. Por exemplo, o Congresso aprova legislação, mas o Presidente tem o poder de vetá-la e o Congresso tem novamente o Poder de descartar o veto. O Judiciário é independente, mas o Presidente nomeia os ministros, que devem ser confirmados pelo Senado.” NOWAK, John E. e ROTUNDA, Ronald D. Constitutional Law. Saint Paul: Thomson West, 2004. p. 149.

${ }^{21}$ LOEWENSTEIN, Karl. Teoria de la Constitución. Barcelona: Editora Ariel 1986. p. 62.
} 
as políticas que atendessem aos seus anseios, diminuindo a participação política e fragilizando, em última instância, o processo democrático ${ }^{22}$.

Nesse aspecto, diversos autores apontam que o fortalecimento da atividade judicial implicaria o declínio da tradicional mobilização política que caracteriza e define a democracia $^{23}$, como desdobramento do aspecto axiológico do ativismo apontado por Humberto Ávila e acima já analisado ${ }^{24}$.

Nesse sentido, apontam esses estudiosos uma tendência quase global à expansão da atividade jurisdicional e até mesmo o advento de uma "juristocracia",25, com a submissão de todas as questões sociais e políticas relevantes à apreciação do Judiciário, o que retiraria do Parlamento a qualidade de instância máxima de deliberação democrática e de definição dos rumos futuros da nação ${ }^{26}$.

22 "The more political questions are decided by the Constitutional Court, the more political alternatives are reduced. Members of Parliament contribute to this development by giving too much consideration to legal arguments in legislation and judges contribute by sometimes exceeding their proper competencies." LANDFRIED, Christine. Germany. in: TATE, C. Neal e VALLINDER, Torbjörn (org.) The Global Expansion of Judicial Power. New York: New York University Press, 1995. p. 307. Também a esse respeito: "Populist constitutional law does not determine the outcomes of political controversies or dictate much about public. policy. Instead, it orients us as we think about and discuss where our country ought to go." TUSHNET, Mark. Taking the Constitution Away From the Courts. Princeton: Princeton University Press, 1999, p. 194.

${ }^{23}$ Não sobre a crítica, mas sobre a íntima relação entre democracia e constitucionalismo, vide BELLAMY, Richard. Policital Constitutionalism: a Republican Defence of the Constitutionality of Democracy. New York: Cambridge University Press, 2007 (versão para kindle). Vide especialmente páginas 90 e seguintes. Ver também ROBERTSON, David. The Judge as Policital Theorist. Princeton: Princeton University Press, 2010 (versão para kindle), p. 8 e ss.

${ }^{24}$ Como exemplo, podemos citar a opinião de Robert Dahl, para quem: "When the court acts within this sphere of fundamental democratic rights, the legitimacy of its actions and its place in the democratic system of government can hardly be challenged. But the more it moves outside this realm - a vast realm in itself - the more dubious its authority becomes. For then it becomes an unelected legislative body. In the guise of interpreting the Constitution - or, even more questionable, divining the obscure and often unknowable intentions of the Framers the high court enacts important laws and policies that are the proper province of elected officials." DAHL, Robert. A. How Democratic is the American Constitution? New Haven: Yale University Press, 2000 (versão para kindle), posição 1209 e seguintes de 1503. No mesmo sentido é a posição de Justice Hand, mencionada e analisada por Bickel, segundo a qual a jurisdição constitucional precisaria ser dotada de limitações graves sob pena de se criar, na realidade, uma "third legislative chamber", ou uma terceira instância legislativa. BICKEL, Alexander M. The Least Dangerous Branch - the Supreme Court at the Bar of Politics. New Haven: Yale University Press, 1962, pp. 46-49.

${ }^{25}$ Em tradução livre do termo "juristocracy" utilizado no seguinte sentido: "Over the past few years the world has witnessed an astonishingly rapid transition to what may be called juristocracy. Around the globe, in more than eighty countries in several supranational entities, constitutional reform has transferred an unprecedented amount of power from representative institutions to judiciaries. The countries that have hosted this expansion of judicial power stretch from the Eastern Bloc to Canada, from Latin America do South Africa, and from Britain to Israel. Most of these countries have a recently adopted constitution or constitutional revision that contains a bill of rights and establishes some form of active judicial review." HIRSCHL, Ran. Towards Juristocracy - the origins and consequences of the new constitutionalism. Cambridge: Harvard University Press, 2007. p. 1.

26 "Por un lado, el control en cuestión significa controlar la actividad legislativa del Parlamento, al que se considera como órgano soberano en toda forma republicana de Estado. Se critica el control del Parlamento porque hace del órgano de control un órgano funcionalmente superior al Parlamento." WRÓBLEWSKI, Jerzy. 
Contudo, essa crítica também a nosso ver é improcedente porque não se pode atribuir ao Poder Legislativo a supremacia máxima em relação aos demais poderes, inclusive em relação ao Judiciário, somente sob o argumento de que essa instância é a que detém a legitimidade popular por ter sido fruto do voto majoritário, porque também não se pode admitir a configuração de uma ditadura das maiorias; ${ }^{27}$ tendo especial relevância, nesse aspecto, o papel contramajoritário da jurisdição constitucional ${ }^{28}$.

Ao nosso ver, a crítica em questão também confunde premissas e acaba por atacar aspectos que não são propriamente atribuíveis ao ativismo judicial, mas fazem parte, isso sim, da própria configuração da jurisdição constitucional e da possibilidade de realização de controle de constitucionalidade ${ }^{29}$.

Isso porque, como defendemos nesse trabalho, apenas pode ser considerado ativismo judicial aquilo que extrapolar as balizas previamente definidas pela própria Constituição como conformadoras da atuação jurisdicional ${ }^{30}$. E é a própria Constituição brasileira, no caso,

Constitución y teoria general de la interpretación jurídica. Madri: Cuadernos Civitas, 1985. P. 97. Ainda sobre a ascensão e o declínio da soberania parlamentar, vide GINSBURG, Tom. Judicial Review in New Democracies Constitutional Courts in Asian Cases. Cambridge: Cambridge University Press, 2003 (versão para kindle), posição 43 e seguintes de 4024.

27 "De fato, a existência da maioria pressupõe, por definição, a existência de uma minoria e, por consequência, o direito da maioria pressupõe o direito à existência de uma minoria. Disto resulta não tanto a necessidade, mas principalmente a possibilidade de proteger a minoria contra a maioria. Esta proteção da minoria é a função essencial dos chamados direitos fundamentais e liberdades fundamentais ou direitos do homem e do cidadão, garantidos por todas as modernas constituições das democracias parlamentaristas." KELSEN, Hans. A Democracia. São Paulo: Martins Fontes, 2000, p. 67.

28 “Costumam-se fazer certas objeções a esse sistema [de jurisdição constitucional]. A primeira, naturalmente, é que tal instituição seria incompatível com a soberania do Parlamento. Mas, à parte o fato de que não se pode falar de soberania de um órgão estatal particular, pois a soberania pertence no máximo à própria ordem estatal, esse argumento cai por terra pelo simples fato de que é forçoso reconhecer que a Constituição regula no fim das contas o processo legislativo, exatamente da mesma maneira como as leis regulam o procedimento dos tribunais e das autoridades administrativas, que a legislação é subordinada à Constituição exatamente como a jurisdição e a administração o são à legislação. E que, por conseguinte, o postulado da constitucionalidade das leis é, teórica e tecnicamente, absolutamente idêntico ao postulado da legalidade da jurisdição e da administração.” KELSEN, Hans. Jurisdição Constitucional. São Paulo: Martins Fontes, 2007. pp. 150-151. Também analisando de forma concreta a constatação de que o sistema republicano não é por si só suficiente para preservar o direito das minorias, vide especificamente quanto ao modelo norte-americano, ELY, John Hart. Democracia $e$ Desconfiança - uma teoria do controle judicial de constitucionalidade. São Paulo: Martins Fontes, 2010. pp. 106-115.

${ }^{29}$ No mesmo sentido, alertando para a possível confusão entre ativismo judicial e as características próprias da jurisdição constitucional, vide: “When we speak of 'judicial activism', we must be careful not to confuse it with the power of judicial review itself. The fact that the judiciary interprets the Constitution and other laws in one way or another is not in itself indicative of judicial activism at all. What the Supreme Court and the lower federal judiciary have been engaged in during the past fifty years is the systematic application of jurisdictional principles derived from the Constitution (and in many cases these derivations have been matters of intense controversy) to the reform of public institutions.” POWERS, Stephen P. E ROTHMAN, Stanley. Op. cit., posição 30 de 3392.

${ }^{30}$ A esse respeito, é interessante a posição de Mark Tushnet no sentido de que, por muitas vezes, é do interesse da própria classe política delegar à Suprema Corte algumas decisões específicas, especialmente no que tange à 
que prevê a possibilidade de realização de controle de constitucionalidade e de fiscalização da legitimidade dos atos do Poder Legislativo pelo Poder Judiciário, inclusive em nítida aplicação da moderna teoria da separação dos poderes, também já devidamente analisada acima.

Portanto, parece-nos que essa espécie de crítica quanto ao ativismo judicial é, primeiramente, melhor aplicável aos países em que não haja previsão específica na Constituição da prerrogativa de controle de constitucionalidade, tendo essa hipótese surgido de interpretação jurisprudencial, ainda que ampla e tradicionalmente consolidada, como é o caso dos Estados Unidos e de sua constituição enxuta e longeva.

Em segundo lugar, acreditamos que essa crítica também não deve ser dirigida ao Judiciário em si, mas ao próprio Legislativo e aos poderes constituintes que elaboraram as constituições hoje vigentes na maioria dos países. Referindo-nos especificamente ao Brasil, seria o Legislativo o destinatário da crítica porque teria sido ele a conformar as balizas de atuação do Poder Judiciário, permitindo e até determinando que ele se portasse como guardião da Constituição, realizando os controles de legitimidade necessários e protegendo a norma fundamental de maiorias inconstitucionais ${ }^{31}$.

Vale ainda dizer que os conceitos utilizados para definir no que se constitui o ativismo não nos parecem compatíveis com as situações geralmente identificadas como ativistas. E isso

declaração de inconstitucionalidade de leis cuja revogação poderia parecer politicamente custosa e impopular pelos próprios membros do Legislativo. TUSHNET, Mark. Why the Constitution Matters. New Haven: Yale University Press, 2010 (versão para kindle), posição 1069 e seguintes de 2135. Esse aspecto, no nosso ver, adiciona elementos à nossa resposta feita à crítica acima, na medida em que corrobora que o Legislativo faz uso político e prático da atividade da Suprema Corte, o que pode até mesmo influencia-lo quando da conformação das balizas de atuação daquele poder, permitindo que ele tenha grandes espaços de atuação.

${ }^{31}$ Também é importante destacar aqui, a crítica de Carl Schmitt no sentido de que o Judiciário não seria a única instância dotada da atribuição de guardar, proteger e tornar eficaz a Constituição, nos seguintes termos: "Se nas constituições alemãs do século XIX está previsto um tribunal especial do Estado para a 'proteção judicial da Constituição' ao lado de outras garantias manifesta-se nelas a simples verdade de que a proteção judicial da Constituição só constitui uma parte das instituições para proteção e garantia da Constituição e que seria uma superficialidade sumária esquecer, por causa dessa proteção judicial, os limites muito estritos de toda judicância e os muitos outros tipos e métodos de uma garantia constitucional." SCHMITT, Carl. O Guardião da Constituição. Belo Horizonte: Del Rey, 2007, p. 15. Concordamos com Schmitt no ponto de que não podemos deixar de considerar as outras instâncias de guarda e proteção da Constituição. Contudo, entendemos que o reconhecimento do importante papel do Judiciário não implica necessariamente o esquecimento da importância das demais instituições, mormente se a atuação judicial se der dentro das balizas conformadoras definidas pelo ordenamento jurídico. No mesmo sentido da posição de Schmitt, Mark Tushnet defende a consolidação de uma jurisdição constitucional fraca ("weak-form review") para permitir que também Executivo e Legislativo ajam como promotores dos valores constitucionais, ressaltando que uma interpretação racional dessas duas instâncias de poder deveria ter o mesmo valor de uma interpretação racional advinda do Judiciário. TUSHNET, Mark. Weak Courts, Strong Rights - judicial review and social welfare rigts in comparative constitutional law. Princeton: Princeton University Press, 2008 (versão para Kindle). pp. 79-81. 
se dá porque, ao nosso ver, parece haver uma nítida confusão entre Judiciário ativista e Judiciário atuante.

Quando se identifica o ativismo judicial em alguma situação concreta sob o argumento de que, nessa situação, teria havido aplicação da técnica de ponderação e de princípios genéricos e sem regulamentação, parece-nos que a crítica não está voltada a uma atuação do Judiciário além das balizas conformadoras da atuação daquele Poder - o que propriamente caracterizaria o ativismo -, mas tão somente está voltada à postura ativa e firme do Judiciário na aplicação de princípios constitucionalmente previstos, em respeito à própria função de guardião da Constituição também prevista na $\mathrm{CF}$ e em atendimento ao dispositivo que impõe que a aplicação de referidos princípios, como direitos fundamentais, seja feita de forma imediata.

Portanto, não nos parece que grande parte dessas identificações possa ser aplicada ao ambiente constitucionalmente conformado no Brasil, pois é a própria Constituição que atribui essas prerrogativas amplas e ativas ao Poder Judiciário, que agindo na aplicação de princípios, por meio da ponderação, apenas cumpre o mandamento constitucional e exerce a sua função.

O Professor Elival da Silva Ramos, por exemplo, aponta algumas situações em que entende ter havido atuação ativista por parte do STF, com as quais não concordamos integralmente.

Na primeira delas, ele indica o precedente em que o Supremo definiu a questão da fidelidade partidária e o mandato como sendo do partido, estipulando algumas exceções.

Para ele, no caso em questão, não obstante tenha a Corte se baseado em princípios constitucionais de representação proporcional e de monopólio das candidaturas pelos partidos, ela extrapolou os limites de sua atuação. Segundo o Professor, o só fato de ter se tratado de argumentação eminentemente fundada em princípios retirou do julgado a sua legitimidade plena e o tornou um exemplo de ativismo ${ }^{32}$.

Para nós, contudo, não se tratou de hipótese de ativismo porque entendemos que a Constituição - ao descrever e elencar princípios e ao determinar que sua aplicação se dê de forma imediata - autoriza essa espécie de conduta e interpretação e até a incentiva; não

\footnotetext{
32 “Como já sucedera no âmbito dessa Justiça especializada, por se cuidar de argumentação centrada em princípios constitucionais, foram alguns dos magistrados votantes procurar apoio no moralismo jurídico e na 'principiologização' do direito, que lhe é característica, para construir a norma de decisão." RAMOS, Elival da Silva. Op. cit., p. 248.
} 
havendo, no caso, atuação que transborde dos limites conferidos pelo ordenamento - quer se concorde ou não com o resultado final.

A segunda situação apontada por Elival da Silva Ramos se refere à elaboração e aprovação da Súmula Vinculante que veda o nepotismo na Administração Pública. Nesse ponto, concordamos com a afirmação do Professor $^{33}$ de que houve uma postura ativista por parte do Supremo Tribunal Federal, uma vez que - não obstante a relevância da matéria e a concordância com a determinação expedida pela Corte - ela transbordou em muito as hipóteses constitucionais que autorizam a edição das súmulas, tendo atuado em total descompasso com os limites constitucionalmente fixados.

Como se percebe, o Poder Judiciário extrapola, em alguns casos concretos, esses poderes e prerrogativas já bem caracterizados acima ${ }^{34}$. Entendemos que apenas nessas hipóteses pode-se falar de Judiciário ativista, retomando-se a definição que acima adotamos, de que o ativismo judicial ocorre quando o Poder Judiciário ultrapassa as balizas de sua atuação normal e regulamentar.

Em todas as outras situações, discordando das críticas expostas e das situações concretas usualmente identificadas, entendemos que não se pode falar de ativismo judicial, mas sim meramente de um Judiciário atuante, o que é escolha, vale dizer, do próprio Poder Constituinte - originário ou reformador - que conformou as balizas de atuação judicial na própria Constituição de forma a conferir ao Poder ora analisado todas as prerrogativas já citadas: aplicação imediata de princípios e direitos fundamentais, o que implica, por si só, a autorização do uso da técnica da ponderação, bem como a edição de súmulas vinculantes e o controle de legalidade e constitucionalidade das leis.

Assim, definidas essas balizas, analisaremos como se pode categorizar a posição do Supremo Tribunal Federal adotada no julgamento da constitucionalidade da Lei Complementar $n^{\circ}$ 135/10, conhecida como a Lei da Ficha Limpa.

\section{Do julgamento da constitucionalidade da Lei da Ficha Limpa}

Quando da análise das ADCs $n^{\circ} 29$ e 30 em conjunto com a ADI $n^{\circ} 4.578$, no que tange ao princípio da presunção de inocência, o Supremo Tribunal Federal analisou se as

\footnotetext{
${ }^{33}$ RAMOS, Elival da Silva. Op. cit., pp. 256-264.

${ }^{34}$ Há até estudiosos que afirmam que "judicial activists are people, judges, who see truths that others so far do not." DOW, David R. America's Prophets - how judicial activism makes America great. Westport, Praeger, 2009 , p. 5.
} 
novas hipóteses de inelegibilidade criadas pela Lei Complementar $n^{\circ} 135 / 10$, notadamente aquelas que incluíam a expressão "ou proferida por órgão colegiado"35 afrontariam esse princípio constitucional, ou se estariam em conformidade com o quanto previsto no artigo 14 , $\S 9^{\circ}$, da Constituição Federal ${ }^{36}$.

Dentre todas as hipóteses em questão, uma delas foi de maior interesse para o exame da suposta ofensa ao princípio. Trata-se da previsão de que se tornariam inelegíveis os cidadãos que houvessem sido condenados por um órgão colegiado - independentemente dessa condenação ser definitiva ou não - por ilícitos penais, eleitorais, ou de improbidade administrativa.

\footnotetext{
${ }^{35}$ Art. $1^{\circ}$ São inelegíveis:

I - para qualquer cargo: (...)

d) os que tenham contra sua pessoa representação julgada procedente pela Justiça Eleitoral, em decisão transitada em julgado ou proferida por órgão colegiado, em processo de apuração de abuso do poder econômico ou político, para a eleição na qual concorrem ou tenham sido diplomados, bem como para as que se realizarem nos 8 (oito) anos seguintes;
}

e) os que forem condenados, em decisão transitada em julgado ou proferida por órgão judicial colegiado, desde a condenação até o transcurso do prazo de 8 (oito) anos após o cumprimento da pena, pelos crimes:

1. contra a economia popular, a fé pública, a administração pública e o patrimônio público;

2. contra o patrimônio privado, o sistema financeiro, o mercado de capitais e os previstos na lei que regula a falência;

3. contra o meio ambiente e a saúde pública;

4. eleitorais, para os quais a lei comine pena privativa de liberdade;

5. de abuso de autoridade, nos casos em que houver condenação à perda do cargo ou à inabilitação para o exercício de função pública;

6. de lavagem ou ocultação de bens, direitos e valores;

7. de tráfico de entorpecentes e drogas afins, racismo, tortura, terrorismo e hediondos;

8. de redução à condição análoga à de escravo;

9. contra a vida e a dignidade sexual; e

10. praticados por organização criminosa, quadrilha ou bando;(..)

h) os detentores de cargo na administração pública direta, indireta ou fundacional, que beneficiarem a si ou a terceiros, pelo abuso do poder econômico ou político, que forem condenados em decisão transitada em julgado ou proferida por órgão judicial colegiado, para a eleição na qual concorrem ou tenham sido diplomados, bem como para as que se realizarem nos 8 (oito) anos seguintes;(...)

j) os que forem condenados, em decisão transitada em julgado ou proferida por órgão colegiado da Justiça Eleitoral, por corrupção eleitoral, por captação ilícita de sufrágio, por doação, captação ou gastos ilícitos de recursos de campanha ou por conduta vedada aos agentes públicos em campanhas eleitorais que impliquem cassação do registro ou do diploma, pelo prazo de 8 (oito) anos a contar da eleição; (...)

1) os que forem condenados à suspensão dos direitos políticos, em decisão transitada em julgado ou proferida por órgão judicial colegiado, por ato doloso de improbidade administrativa que importe lesão ao patrimônio público e enriquecimento ilícito, desde a condenação ou o trânsito em julgado até o transcurso do prazo de 8 (oito) anos após o cumprimento da pena; (...)

p) a pessoa física e os dirigentes de pessoas jurídicas responsáveis por doações eleitorais tidas por ilegais por decisão transitada em julgado ou proferida por órgão colegiado da Justiça Eleitoral, pelo prazo de 8 (oito) anos após a decisão, observando-se o procedimento previsto no art. 22;

${ }^{36} \S 9^{\circ}$ Lei complementar estabelecerá outros casos de inelegibilidade e os prazos de sua cessação, a fim de proteger a probidade administrativa, a moralidade para exercício de mandato considerada vida pregressa do candidato, e a normalidade e legitimidade das eleições contra a influência do poder econômico ou o abuso do exercício de função, cargo ou emprego na administração direta ou indireta. (Redação dada pela Emenda Constitucional de Revisão no 4, de 1994) 
Como se percebe do dispositivo acrescentado pela Lei Complementar $n^{\circ} 135 / 10$, o legislador promoveu uma flexibilização do princípio da presunção de inocência ao permitir que se aplicasse ao cidadão uma sanção - a de não poder se candidatar, alijando-o da plena participação do processo político - antes mesmo que se confirmasse essa condenação como definitiva.

Essa inovação legislativa, frente à jurisprudência até então consolidada pelo Supremo Tribunal Federal aparentava ter todas as características de inconstitucionalidade a serem reconhecidas pelo Tribunal no momento em que provocado.

Todavia, surpreendentemente, a Corte Suprema entendeu constitucional o referido dispositivo, mediante uma análise que pode ser resumida da seguinte forma.

Inicialmente, entenderam os Ministros, acompanhando o Ministro Relator Luiz Fux, que o direito de ser votado - ius honorum - não pode ser equiparado com direitos políticos lato sensu, de forma que a suspensão do exercício dessa prerrogativa não poderia ser considerada uma punição propriamente dita. Isso porque, segundo o raciocínio desenvolvido pela Corte, os cidadãos têm mera expectativa de direto à candidatura, a qual somente se concretiza quando há a comprovação do atendimento aos requisitos legais e constitucionais de elegibilidade.

Assim, a impossibilidade de ser votado, aferida no momento em que registrada a candidatura, não representaria a aplicação de uma sanção e não deveria observar a interpretação restritiva do princípio da presunção de inocência conferida aos ilícitos penais pelo próprio Supremo Tribunal Federal.

Nesse exato sentido, foi a seguinte manifestação do Ministro Luiz Fux, relator do processo:

Questiona-se, então: é razoável a expectativa de candidatura de um indivíduo já condenado por decisão colegiada? A resposta há de ser negativa. Da exigência constitucional de moralidade para o exercício de mandatos eletivos (art. $14, \S 9^{\circ}$ ) se há de inferir que uma condenação prolatada em segunda instância ou por um colegiado no exercício da competência de foro por prerrogativa de função, a rejeição de contas públicas, a perda de cargo público ou o impedimento do exercício de profissão por violação de dever éticoprofissional excluirão a razoabilidade da expectativa. A rigor, há de se inverter a avaliação: é razoável entender que um indivíduo que se enquadre em tais hipóteses qualificadas não esteja, a priori, apto a exercer um mandato eletivo. 
Como se percebe da manifestação acima, a premissa utilizada pelo Supremo Tribunal Federal para relativizar a aplicação do princípio da presunção de inocência funda-se na consideração de que o direito de ser votado é, na realidade, uma mera expectativa de direito, a ser concretizada mediante a análise do preenchimento de requisitos legais e constitucionais, a ser feita no momento do registro da candidatura.

E partindo dessa premissa, permite-se a conclusão de que, no caso concreto, deve-se conferir prevalência ao princípio da moralidade para o exercício de cargos públicos, previsto constitucionalmente pelo $\S 9^{\circ}$, do artigo 14, da Constituição Federal, frente ao interesse privado de se eleger, o qual sequer poderia ser considerado como um direito em si, mas meramente como uma expectativa de direito.

Ademais, a ponderação realizada pelo Ministro Relator contrapôs de um lado da balança os direitos políticos passivos e, do outro, os princípios da moralidade e da própria democracia, tendo ele concluído que a balança certamente deveria pender para o segundo lado, tendo em vista não haver sequer lesão ao núcleo essencial dos direitos políticos, uma vez que, no caso em questão, tratava-se de mera relativização apenas da faceta passiva (de candidatar-se e de ser votado) desses direitos.

E ainda no tocante à ponderação, alegou o Ministro Relator a necessidade de se conferir validade à "ponderação efetuada pelo próprio legislador", sendo hipótese de “interpretação da Constituição conforme a lei”, inclusive pela colocação de conceitos indeterminados no diploma constitucional, como "vida pregressa".

Para tanto, o STF perquiriu a aplicabilidade e irradiação do princípio da presunção de inocência - positivado no inciso LVII, artigo $5^{\circ}$, da CF - ao processo eleitoral, revisitando o entendimento que havia sido firmado no julgamento da ADPF $\mathrm{n}^{\circ} 144$, em que o Ministro Relator, Celso de Mello, houvera afirmado a aplicação do referido princípio também ao processo eleitoral, como decorrência lógica da cláusula constitucional do Estado Democrático de Direito $^{37}$.

Vale dizer que todo o juízo desenvolvido e o próprio resultado a que se chegou, decorreu também de uma análise de aplicabilidade e adequação da interpretação constitucional ao estado espiritual do povo brasileiro como então entendido pelo Supremo Tribunal Federal. Chegou a afirmar o Ministro Relator que "ou bem se realinha a

\footnotetext{
${ }^{37}$ A esse respeito, o Ministro Luiz Fux justificou o "overruling dos precedentes relativos à material da presunção de inocência vis-à-vis inelegibilidades" em decorrência de uma suposta "incongruência sistêmica ou social".
} 
interpretação da presunção de inocência, ao menos em termos de Direito Eleitoral, com o estado espiritual do povo brasileiro, ou se desacredita a Constituição”.

$\mathrm{Na}$ mesma toada, propôs o Eminente Ministro que o STF adotasse um constitucionalismo democrático, não se furtando a dar ouvidos aos anseios populares e às contestações e divergências surgidas no seio social em relação às suas decisões e, ao mesmo tempo, não abandonando o seu papel contramajoritário de proteção aos direitos fundamentais.

A fundamentação do voto do Ministro Luiz Fux também passou pela consideração de que a cláusula constitucional da presunção de inocência não teria conteúdo principiológico, mas seria mera regra, de forma que a interpretação extensiva anteriormente conferida pela Corte ao referido dispositivo deveria ser novamente reduzida - por meio de uma denominada redução teleológica - para que sua interpretação pudesse reencontrar o seu sentido inicial e literal, de regra que não admite a mesma extensão interpretativa que os princípios ${ }^{38}$.

E em decorrência do raciocínio acima exposto, o próprio Ministro Relator já rechaçou a possibilidade de que sua interpretação pudesse configurar violação ao princípio da vedação do retrocesso, segundo o qual não pode uma norma legal posterior restringir o grau de concretização legislativa de um princípio fundamental alcançado anteriormente. E rechaçou essa possibilidade sob o fundamento de que não havia consenso básico social acerca da aplicabilidade da presunção de inocência às questões eleitorais e de que a restrição ora imposta pela Lei Complementar $n^{\circ} 135 / 10$ seria razoável e proporcional, diante da concretização do princípio da moralidade disposto no $\S 9^{\circ}$, do artigo 14 , da CF.

Ainda como reforço de argumentação, o Ministro Relator afirmou que uma interpretação sistemática dos dispositivos constitucionais também levaria à conclusão da constitucionalidade das hipóteses de inelegibilidade previstas pela Lei Complementar $\mathrm{n}^{\mathbf{o}}$ 135/10, uma vez que o artigo 15 da Constituição Federal já prevê a perda dos direitos políticos (ativos e passivos) com a condenação definitiva em processo criminal ou por improbidade administrativa, de forma que a previsão do $\S 9^{\circ}$, do artigo 14 , da Constituição Federal, somente poderia ter efetividade e lógica caso se permitisse incluir, pela legislação complementar, hipóteses de perda ou suspensão dos referidos direitos por meio de decisões ainda não definitivas.

\footnotetext{
38 "Destarte, reconduzir a presunção de inocência aos efeitos próprios da condenação criminal se presta a impedir que se aniquile a teleologia do art. $14, \S 9^{\circ}$, da Carta Política, de modo que, sem danos à presunção de inocência, seja preservada a validade de norma cujo conteúdo, como acima visto, é adequado a um constitucionalismo democrático". Voto do Ministro Luiz Fux, Relator da ADI n 4.578
} 
Assim, votou o Ministro Relator, Luiz Fux, pela constitucionalidade dos dispositivos da Lei Complementar $n^{\circ}$ 135/10 que adicionaram novas hipóteses de inelegibilidade ao ordenamento jurídico nacional.

Em seguida, o Ministro Joaquim Barbosa apresentou o seu voto-vista, em que acompanhou o Ministro Relator, conferindo especial relevância à mobilização social que deu origem à Lei Complementar $\mathrm{n}^{\circ}$ 135/10, afirmando que o movimento que subsistiu "[r]evela, sobretudo, um despertar de consciência a respeito do real significado da democracia e de um dos elementos constitutivos essenciais que é a representação política".

E na mesma toada, afirmou analisar o referido normativo sob a ótica da prevalência do interesse público e da valorização da moralidade e não para fins de proteção de interesses individuais e privados, afirmando, no caso, dever haver nítida separação entre as esferas pública e privada e a conferência de prioridade à primeira.

Em seguida votou o Ministro Dias Toffoli, que inaugurou a divergência, iniciando sua argumentação pela análise do papel contramajoritário que deve exercer o STF e pela importância da faceta passiva do direito político - ius honorum - e da necessidade de se conferir prevalência a ela, sob pena de se restringir a ampla participação democrática no processo eleitoral.

Afirmou, ainda, que a prevalência do interesse público sobre o individual não poderia culminar com a anulação desse último e que a manutenção das expressões "ou proferida por órgão colegiado" e "ou proferida por órgão colegiado da Justiça Eleitoral” implicariam ofensa ao postulado da presunção de inocência e consequente violação de direito individual.

Concluiu que, em consequência mesmo dessa violação ao princípio da presunção de inocência, ao permitir que condenações ainda não definitivas operassem seus efeitos, haveria também transgressões aos postulados da segurança jurídica e da isonomia.

Reportou-se ao quanto restou definido pelo Supremo Tribunal Federal no julgamento do $\mathrm{HC} \mathrm{n}^{\circ}$ 84.078/MG - que definiu abrangência ampla à garantia da presunção de inocência , e argumentou que o próprio artigo 15, inciso III, da Carta Política, não permite que o preso provisório perca os seus direitos políticos, mas o advento da Lei Complementar passaria a permitir que a provisoriedade de uma sentença seria suficiente para tornar o indivíduo processado inelegível. 
Argumentou, ainda, o Ministro Dias Toffoli, em seu voto divergente, que a previsão do artigo 26- $\mathrm{C}^{39}$ da Lei Complementar não seria suficiente para impedir eventuais incongruências, mas pelo contrário, representaria incongruências ainda mais evidentes, uma vez que significaria regra de inversão do postulado da presunção de inocência, fragilização desse mesmo postulado, injustiça dos dispositivos legais e oportunidade de conferência de poderes excessivos aos juízes, que podem acabar sendo os responsáveis por definir aqueles que poderão ou não participar da disputa eleitoral, com base em critérios subjetivos que muitas vezes serão questionáveis.

Ressalte-se aqui que estamos a nos cingir aos argumentos que tinham relação com o direito fundamental à presunção de inocência, sendo certo que muitos outros aspectos discutidos nos votos não foram e não serão detalhados aqui, por fugirem ao ponto que queremos provar.

A Ministra Rosa Weber acompanhou o voto do Ministro Relator também forte na premissa de que a inelegibilidade não configura uma pena em si, muito menos teria característica penal, sendo evidente, então, o objetivo da Lei Complementar $n^{\circ}$ 135/10 de fazer valer os princípios da probidade e da moralidade cujo atendimento o $\$ 9^{\circ}$ do artigo 14 da $\mathrm{CF}$ delegou à lei complementar definir ${ }^{40}$.

E quanto ao papel contramajoritário do STF, afirmou a Ministra que o Tribunal não poderia ser insensível às aspirações da maioria, já que, "em uma democracia pluralista, todos compõem a sociedade aberta dos intérpretes da Constituição” e, por essa razão, as opiniões diversas devem ser sempre levadas em consideração para se construir uma interpretação consentânea com a unicidade da Constituição Federal. No mesmo sentido votaram a Ministra Cármen Lúcia, o Ministro Ricardo Lewandowski e o Ministro Carlos Ayres Britto.

\footnotetext{
39 "Art. 26-C. O órgão colegiado do tribunal ao qual couber a apreciação do recurso contra as decisões colegiadas a que se referem as alíneas $d, e, h, j, l$ e $n$ do inciso I do art. $1^{\circ}$ poderá, em caráter cautelar, suspender a inelegibilidade sempre que existir plausibilidade da pretensão recursal e desde que a providência tenha sido expressamente requerida, sob pena de preclusão, por ocasião da interposição do recurso.

$\S 1^{\circ}$ Conferido efeito suspensivo, o julgamento do recurso terá prioridade sobre todos os demais, à exceção dos de mandado de segurança e de habeas corpus.

$\S 2^{\circ}$ Mantida a condenação de que derivou a inelegibilidade ou revogada a suspensão liminar mencionada no caput, serão desconstituídos o registro ou o diploma eventualmente concedidos ao recorrente.

$\S 3^{\circ}$ A prática de atos manifestamente protelatórios por parte da defesa, ao longo da tramitação do recurso, acarretará a revogação do efeito suspensivo."

${ }^{40}$ Segundo a Ministra Rosa Weber afirmou em seu voto: "O escopo da inelegibilidade não é punir. A norma jurídica não tem no indivíduo seu destinatário primeiro - outro o foco - é sim a coletividade, buscando preservar a legitimidade das eleições, a autenticidade da soberania popular e, em última análise, a assegurar o processo de concretização do Estado Democrático de Direito".
} 
Em seguida, foi a vez de o Ministro Gilmar Mendes proferir seu voto, que acompanhou a divergência inaugurada pelo Ministro Dias Toffoli. O Ministro destacou que a presunção de inocência é um postulado estabelecido constitucionalmente em favor das pessoas contra "abuso de poder e a prepotência do Estado" e por isso é garantia da mais ampla importância, devendo ser respeitada e irradiada para outros âmbitos que não apenas o penal.

Em seguida, contrapondo-se ao voto do relator, o Ministro Gilmar Mendes fez uma digressão acerca da democracia crítica, cuja concepção alerta para os riscos de uma “divinização do povo", reforçando a necessidade de se assumir que também o povo é falível, assim como todo e qualquer cidadão. E na mesma toada, a respeito da relevância que os demais Ministros conferiram ao fato de a $\mathrm{LC} \mathrm{n}^{\mathrm{o}}$ 135/10 ter origem em iniciativa popular, assim afirmou em seu voto:

O argumento de que a lei é de iniciativa popular não tem peso suficiente para minimizar ou restringir o papel contramajoritário da Jurisdição Constitucional. É compreensível a ação das várias organizações sociais tendo em vista a repercussão que esse tema da 'ficha-limpa' tem na opinião pública. Sabemos que, para temas complexos em geral, há sempre uma solução simples e em geral errada. E para esse caso a população passa a acreditar que a solução para a improbidade administrativa, para as mazelas da vida política, é a Lei da Ficha Limpa. A partir daí há, na verdade, a tentativa de aprisionar, o que nos dificulta enormemente a missão nesta Corte, como em outros casos, porque acabamos tendo de nos pronunciar de forma contramajoritária, claro, tendo em vista a opinião pública, segundo as pesquisas manifestadas de opinião. Mas a missão desta Corte é aplicar a Constituição, ainda que contra a opinião majoritária. Esse é o ethos de uma Corte Constitucional. É fundamental que tenhamos essa visão.

Assim, no caso específico, manifestou o Ministro que não compete ao STF relativizar princípios constitucionais para atender aos anseios populares, ressaltando que as decisões contramajoritárias eventualmente tomadas pela Corte Suprema costumam originar movimentos de diálogo institucional, com debates intensos sobre as questões no meio social e político.

Ademais, focou o Ministro outro importante argumento até então não aventado por nenhum de seus outros pares, no sentido de que o regime democrático confere aos cidadãos, ao povo em geral, mecanismos outros de controle da moralidade no âmbito político, sendo o primeiro e mais elementar desses mecanismos o próprio voto. 
Outro mecanismo de controle seria a própria nomeação dos candidatos feita pelos partidos políticos, os quais têm importância ímpar no processo democrático, conferida e assegurada constitucionalmente.

Ademais, reforçou o Ministro que o postulado da não culpabilidade (ou da inocência), ao contrário do quanto afirmado pelo Ministro Relator, não poderia ser considerado uma regra, mas sim efetivamente um princípio, tanto pela sua estrutura normativa, como pela sua forma de aplicação e pelo seu caráter fundamental.

Refutou, ainda, o Ministro, os argumentos no sentido de que os julgamentos por órgãos colegiados se revestiriam de certeza e segurança jurídica, uma vez que se encerraria em segunda instância a possibilidade de análise fático-probatória.

Importante notar que também outra premissa constante nos votos proferidos pelo Ministro Relator e por aqueles que o acompanharam foi rechaçada pelo Ministro Gilmar Mendes. Para ele, a perda do direito político passivo (ius honorum), considerada de menor importância pelos Ministros filiados ao outro lado da controvérsia, seria uma "espécie de nulificação da própria cidadania, ainda que temporariamente”, uma vez que os direitos políticos, em todas as suas facetas -- passiva ou ativa -- correspondem ao direito amplo de participação na vida política do país, sendo essenciais à "saúde da vida democrática".

Em seguida, votou o Ministro Marco Aurélio que acompanhou o Ministro Relator no aspecto atinente à inexistência de violação ao princípio da presunção de inocência. Votaram, então, o Ministro Celso de Mello e o Ministro Cezar Peluso, os quais acompanharam a divergência.

Contudo, restou vencedora a posição do Ministro Relator pela constitucionalidade da lei, vencidos os Ministros Dias Toffoli, Gilmar Mendes, Celso de Mello e Cezar Peluso.

\section{Da postura ativista do Supremo Tribunal Federal no julgado acima analisado}

Como se observa do resultado e das discussões ocorridas no julgamento da constitucionalidade da chamada Lei da Ficha Limpa, o Supremo Tribunal Federal flexibilizou a extensão do princípio da presunção de inocência, permitindo restrições aos direitos políticos dos cidadãos condenados por colegiados, ainda que referida condenação fosse passível de revisão por meio de recurso. 
As inconsistências do referido julgamento são muito claras diante da constatação da relevância do princípio da presunção de inocência para a dignidade da pessoa humana e para o Estado Democrático de Direito.

Tanto é verdade que, a nosso ver, o Supremo Tribunal Federal precisou relativizar a extensão dos direitos políticos para permitir que, na ponderação de valores realizada no exame da constitucionalidade da norma em si, a balança pendesse contrariamente ao princípio da presunção de inocência.

Dessa forma, parece-nos que, não obstante tenha a Corte adotado a técnica de interpretação de direitos fundamentais que entendemos como a mais adequada, ela não foi aplicada com a racionalidade necessária, pois as premissas adotadas para sopesar os direitos em conflito acabaram por desnaturar um deles, o que prejudicou o processo e o resultado da ponderação.

Estamos nos referindo especificamente à diferenciação feita inicialmente pelo Ministro Relator entre direitos políticos passivos e ativos, dotando-se os últimos de uma maior relevância do que os primeiros. Para essa corrente que se sagrou majoritária no Supremo, o direito de votar seria postulado supremo da democracia, ao passo que o direito de ser votado seria mera expectativa de direito, de hierarquia inferior à sua faceta ativa.

E foi precisamente essa distorção do significado dos direitos políticos que permitiu o resultado a que chegou o Supremo, em que se conferiu prevalência aos princípios da moralidade e da democracia frente a direitos políticos despidos de sua real significação; portanto, enfraquecidos no conflito resolvido pela Corte.

Fica claro, da análise acima, que o resultado a que chegou o Tribunal, derivado do seu juízo de ponderação, não pode ser considerado racional porque falha no seu processo de justificação extern ${ }^{41}$ ao realizar distorções de premissas, prejudicando todo o desenvolvimento da técnica interpretativa.

Outra inconsistência que nos pareceu flagrante no julgamento foi a afirmação de que, na realização do juízo de ponderação, deveria ser conferida prevalência à própria ponderação

\footnotetext{
${ }^{41} \mathrm{Na}$ sua teoria da argumentação - por meio da qual comprova a racionalidade do seu método de ponderação --, Alexy fixa-se na justificação externa, por ser ela a originar propriamente, de forma purista, a argumentação jurídica. Ele divide, então, seis tipos de regras e formas de justificação externa: (i) lei, ou interpretação; (ii) Ciência do Direito, ou dogmática; (iii) precedente; (iv) razão, ou argumentação prática geral; (v) empiria; e (vi) formas especiais de argumentos jurídicos. ALEXY, Robert. Teoria da Argumentação Jurídica - A teoria do discurso racional como teoria da justificação jurídica. São Paulo: Landy, 2005, pp. 227-273.
} 
feita pelo legislador ordinário quando da promulgação da lei, em detrimento do princípio constitucional apontado como violado.

Ora, a Corte Constitucional reafirmou, ao longo de sua história, a importância do seu papel contramajoritário na preservação da máxima eficácia dos direitos fundamentais quando confrontados com legislação que, a despeito de ter sido aprovada pela maioria do Congresso e de ter evidente apoio popular, confrontava com algum dispositivo constitucional. Todavia, nesse caso específico, preferiu o Supremo ignorar esse papel.

Não estamos aqui a afirmar que a Corte tem sempre que assumir função contramajoritária, mas apenas que no presente caso esse era o papel que ela deveria ter assumido, mesmo porque a argumentação utilizada por ela para reconhecer a constitucionalidade do dispositivo invocado precisou contar com a flexibilização do próprio conceito e extensão dos direitos políticos, tendo a ponderação em si representado inadequada e desproporcional restrição ao princípio da presunção de inocência, por meio da desnaturação dos direitos políticos fundamentais.

Ou seja, a própria ponderação em si foi totalmente desconfigurada, pois ela é uma técnica que visa exatamente a evitar que os princípios fundamentais, quando em conflito, tenham seu conteúdo essencial atingido. E no caso concreto, o próprio Supremo feriu conteúdo essencial dos direitos políticos para chegar a um resultado de ponderação que, automaticamente, também prejudicou a plena eficácia do princípio da presunção de inocência.

E ao contrário do que argumentou o Ministro Relator, entendemos que a nova posição do Supremo referente à extensão do princípio da presunção de inocência no presente caso representou efetiva afronta à proibição de retrocesso, uma vez que reduziu o nível de concreção normativa a que tinha chegado o princípio tanto no julgamento do HC 84078, quando no julgamento da ADPF 144, que houvera decidido pela sua aplicabilidade também no âmbito eleitoral.

Vale dizer que, na linha oposta à defendida pelo Relator, a presunção de inocência não é regra, mas sim efetivo princípio cuja efetividade depende do significado que lhe é atribuído por seus intérpretes. Portanto, aqui se verifica mais uma tentativa de burlar as premissas para conseguir uma pretensa fundamentação do resultado pretendido, o qual se torna, consequentemente e desde logo, improcedente e carente de racionalidade.

Além disso, foi argumento frequente no julgamento a supremacia do interesse público sobre o interesse privado dos cidadãos de se candidatar para o exercício de cargos públicos. 
Contudo, referido argumento é também frágil, uma vez que não se vislumbra, na atual configuração constitucional e social, uma nítida e estanque separação entre o público e o privado, sendo evidente que os direitos políticos, além de dimensão privada, têm nítida conformação pública, porque dizem respeito diretamente ao exercício da democracia e à plena configuração do Estado de Direito.

É importante notar que todas essas manobras nas premissas interpretativas que permitiram a conclusão a que chegou o Ministro Relator foram justificadas, ao nosso ver, pela pressão política exercida por diversos setores da sociedade em favor da aprovação da Lei da Ficha Limpa.

Foi referido instrumento legal uma das únicas quatro leis de iniciativa popular aprovadas na história da Constituição, o que aos olhos do Supremo deve ter-lhe conferido legitimidade adicional quando do enfrentamento de sua constitucionalidade.

Contudo, a participação popular na aprovação da lei não tem o condão de flexibilizar violação a princípios constitucionais, mormente quando revestidos de fundamentalidade indiscutível e de importância basilar para a consolidação do Estado Democrático de Direito.

A despeito de todas essas razões, o Supremo Tribunal Federal houve por bem alterar novamente a interpretação do princípio da presunção da inocência, ainda que tivesse buscado focar o conflito de interesses em jogo ao embate entre o direito político passivo e os princípios da moralidade e da democracia.

\section{Reflexões conclusivas}

Por fim, observando a distorção de premissas que possibilitaram o juízo de ponderação predominante no resultado final e diante das definições e considerações sobre o ativismo judicial que fizemos nas seções introdutórias do presente trabalho, entendemos que a constitucionalidade da Lei da Ficha Limpa, no tocante às análises de violação ao princípio da presunção de inocência, é um exemplo de ativismo judicial.

Isso porque, conforme já amplamente debatido acima, o ativismo judicial caracterizase quando há a interpretação e aplicação de direitos pelo Supremo Tribunal Federal em atuação que exacerba os limites definidos pelo ordenamento jurídico.

À primeira vista, poderia o leitor afirmar que, no caso da Lei da Ficha Limpa, a Corte simplesmente realizou os juízos de ponderação por nós mesmos defendidos e que, contudo, 
tendo chegado a resultado incompatível com o almejado por nós, levou-nos a atribuir a pecha de ativista à decisão.

De fato, se realmente tivesse ocorrido apenas isso, não haveria que se falar em ativismo. Todavia, entendemos que o que ocorreu foi o mascaramento das premissas de fundamentação com a distorção de sentido dos princípios em jogo em articulada tentativa que buscou, no nosso sentir, simplesmente chancelar as expectativas populares no tocante à aprovação e constitucionalidade da Lei da Ficha Limpa.

Agindo dessa forma - privilegiando os anseios populares em detrimento dos princípios constitucionais fundamentais e utilizando-se, para tanto, de premissas equivocadas e distorcidas sobre os fatos e princípios em jogo -, o Supremo Tribunal Federal extrapolou os limites de atuação que lhe impõe a própria Constituição, acabando por representar a sua violação, ao invés de sua guarda.

\section{Referências bibliográficas}

ALEXY, Robert. Teoria da Argumentação Jurídica - A teoria do discurso racional como teoria da justificação jurídica. São Paulo: Landy, 2005.

Teoría de los Derechos Fundamentales. Madrid: Centro de Estudios Politicos y Constitucionales, 2007.

ÁVILA, Humberto. Neoconstitucionalismo: entre a "ciência do direito" e o "direito da ciência”. in: Vinte anos da Constituição Federal de 1988. Rio de Janeiro: Lumen Juris, 2009.

BARCELlOS, Ana Paula de. Alguns Parâmetros Normativos para a Ponderação Constitucional. in: BARROSO, Luís Roberto (org.) A Nova Interpretação Constitucional Ponderação, Direitos Fundamentais e Relações Privadas. Rio de Janeiro: Renovar, 2006.

BELLAMY, Richard. Policital Constitutionalism: a Republican Defence of the Constitutionality of Democracy. New York: Cambridge University Press, 2007 (versão para kindle).

BICKEL, Alexander M. The Least Dangerous Branch - the Supreme Court at the Bar of Politics. New Haven: Yale University Press, 1962.

BRANCO, Paulo Gustavo Gonet. Juízo de Ponderação na Jurisdição Constitucional. São Paulo: Saraiva, 2009.

CARBOnELL, Miguel. Prólogo: nuevos Tiempos Para El Constitucionalismo. in: CARBONELL, Miguel (org.) Neoconstitucionalismo(s). Madrid: Editorial Trotta, 2009. 
CARRESE, Paul O. The Cloaking of Power - Montesquieu, Blackstone and the Rise of Judicial Activism. Chicago: The University of Chicago Press, 2003.

COMELLA, Víctor Ferreres. Constitutional Courts \& Democratic Values - a european perspective. New Haven: Yale University Press, 2009.

DAHL, Robert. A. How Democratic is the American Constitution? New Haven: Yale University Press, 2000 (versão para kindle).

DOW, David R. America's Prophets - how judicial activism makes America great. Westport, Praeger, 2009.

DWORKIN, Ronald. Levando os Direitos a Sério. São Paulo: Martins Fontes, 2007.

ELY, John Hart. Democracia e Desconfiança - uma teoria do controle judicial de constitucionalidade. São Paulo: Martins Fontes, 2010.

FERREIRA FILHO, Manoel Gonçalves. O Papel Político do Judiciário e suas Implicações. in: Systemas, Revista de Ciências Jurídicas e Econômicas. Ano 1, n. 2. Disponível em: http://www.revistasystemas.com.br/index.php/systemas/article/view/21/16. Acesso em 24.03.2014.

GINSBURG, Tom. Judicial Review in New Democracies - Constitutional Courts in Asian Cases. Cambridge: Cambridge University Press, 2003 (versão para kindle).

HIRSCHL, Ran. Towards Juristocracy - the origins and consequences of the new constitutionalism. Cambridge: Harvard University Press, 2007.

KELSEN, Hans. A Democracia. São Paulo: Martins Fontes, 2000. Jurisdição Constitucional. São Paulo: Martins Fontes, 2007.

LANDFRIED, Christine. Germany. in: TATE, C. Neal e VALLINDER, Torbjörn (org.) The Global Expansion of Judicial Power. New York: New York University Press, 1995.

LEWIS, Frederick P. The Context of Judicial Activism - the endurance of the Warren Court legacy in a Conservative Age. Lanham: Rowman \& Littlefield Publisher Inc., 1999.

LOEWENSTEIN, Karl. Teoria de la Constitución. Barcelona: Editora Ariel 1986.

MORESO, José Juan. Conflictos entre Principios Constitucionales. in: CARBONELL, Miguel (org.) Neoconstitucionalismo(s). Madrid: Editorial Trotta, 2009.

NOWAK, John E. e ROTUNDA, Ronald D. Constitutional Law. Saint Paul: Thomson West, 2004.

POWERS, Stephen P. E ROTHMAN, Stanley. The Least Dangerous Branch? Consequences of Judicial Activism. Westport: Praeger, 2002 (versão para kindle). 
RAMOS, Elival da Silva. Ativismo Judicial. Parâmetros Dogmáticos. São Paulo: Saraiva, 2010.

REHNQUIST, William H. The Supreme Court. New York: Vintage Books, sem indicação de ano (versão para Kindle).

ROBERTSON, David. The Judge as Policital Theorist. Princeton: Princeton University Press, 2010 (versão para kindle).

ROOSEVELT III, Kermit. The Myth of Judicial Activism - making sense of Supreme Court Decisions. New Haven: Yale University Press, 2006 (versão para kindle).

SARLET, Ingo Wolfgang. A Eficácia dos Direitos Fundamentais. Porto Alegre: Livraria do Advogado, 2007.

SCHMITT, Carl. O Guardião da Constituição. Belo Horizonte: Del Rey, 2007.

SILVA, Virgílio Afonso da. Direitos Fundamentais - conteúdo essencial, restrições e eficácia. São Paulo: Malheiros, 2009.

SUTHERLAND, Mark I. Redefining the Rules. In: SUTHERLAND, Mark I. (org.) Judicial Tyranny - the new kings of america? Saint louis: Amerisearch, 2007 (versão para kindle).

TUSHNET, Mark. Taking the Constitution Away From the Courts. Princeton: Princeton University Press, 1999.

Weak Courts, Strong Rights - judicial review and social welfare rigts in comparative constitutional law. Princeton: Princeton University Press, 2008 (versão para Kindle).

para kindle).

Why the Constitution Matters. New Haven: Yale University Press, 2010 (versão

Artigo recebido em 29 de maio de 2014.

Artigo aprovado para publicação em 08 de junho de 2014.

DOI: $10.11117 / 1982-4564.07 .06$ 